\title{
STRATEGI PEMASARAN KOPI LUWAK MANGLAYANG KARLINA DI KELOMPOK TANI KIWARI FARMERS, KABUPATEN BANDUNG
}

\author{
Kuswarini Kusno,', M. Indra Pratama Arifin ${ }^{2}$, Sulystiodewi Nur Wiyono ${ }^{1}$, Dini \\ Rochdiani $^{1}$ \\ ${ }^{1}$ Fakultas Pertanian, Universitas Padjadjaran \\ ${ }^{2}$ Alumnus Fakultas Pertanian Universitas Padjadjaran \\ kuswarini.kusno@unpad.ac.id
}

\begin{abstract}
Abstrak
Kiwari Farmers adalah kelompok tani yang mengusahakan kopi arabika reguler dan kopi luwak Manglayang Karlina. Penjualan kopi luwaknya rendah dan tidak kontinyu selama tahun 2016-2017. Karena itu perlu diidentifikasi penyebabnya dengan tujuan untuk merumuskan strategi pemasaran kopi luwak tersebut di Kelompok Tani Kiwari Farmers. Teknik penelitian menggunakan teknik studi kasus. Data primer dan sekunder dikumpulkan melalui observasi, wawancara, dan studi literatur. Data dianalisis dengan analisis strength, weakness, opportunity, and threat (SWOT) dan Quantitative Strategic Planning Matrix (QSPM). Hasil penelitian menunjukkan ada 6 strategi alternatif: 1) mengalokasikan keuntungan untuk riset fermentasi biji kopi, dan proses roasting, untuk pelatihan formal tenaga kerja, serta untuk pembangunan lantai jemur dan gudang, 2) melakukan kampanye kreatif berbasis edukasi mengenai animal welfare, dan jenis, manfaat serta proses pengolahan kopi luwak, 3) menggunakan Instagram dan Facebook untuk mengedukasi konsep pengolahan mandiri dari hulu hingga hilir dan animal welfare, 4) memperluas jalan kebun, lantai jemur, dan tempat pengolahan pasca panen kopi untuk kepentingan agrowisata, 5) meningkatkan riset pengolahan roasting dan pelatihan tenaga kerja, serta 6) mempertahankan dan menambah inovasi produk baru dan kemasan. Strategi prioritas atau yang terbaik adalah strategi kesatu.
\end{abstract}

Kata kunci: kopi luwak, strategi pemasaran, SWOT, QSPM

\begin{abstract}
Kiwari Farmers cultivates for regular Arabica coffee and Manglayang Karlina Luwak coffee in Bandung district. The sales volume of civet coffee is still low and has experienced discontinue sales during 2016-2017. Thus, it is necessary to identify the causes of the low sales of civet coffee in order to formulate the marketing strategy of the civet coffee in the Kiwari Farmers Group. This study uses case study techniques. Primary and secondary data are collected through observation, interviews, and literature studies. Data on strengths, weaknesses, opportunities and threats encountered by Kiwari farmers groups were analyzed using SWOT Analysis and Quantitative Strategic Planning (QSP) Matrix. As a result, there were six alternative strategies: 1) allocate profits for coffee bean fermentation research, roasting processes, formal labor training, building dry floors and warehouses, 2) create creative campaigns such as the animal welfare education campaign, and campaigns on civet coffee types, the benefits of civet coffee consumption, and the processing of civet coffee, 3) use the benefits of social media in particular Instagram and Facebook to educate the concept of civet coffee processing from the beginning to the end of the process, and animal welfare, 4) enlarge the road area in the garden, drying area, build a post-harvest site and processing coffee for the development of an agro-tourism business unit, 5) improve roasting processing research and employee training, and 6) maintain by innovating new products and packaging. The best strategy is strategy number 1) mentioned above. Kiwari
\end{abstract}

Keywords: civet coffee, marketing strategy, SWOT, QSPM 


\section{Pendahuluan}

Pertanian Indonesia terdiri dari sub sektor pangan, hortikultura, perkebunan, perikanan dan peternakan (Soetrisno, 2002). Salah satu sub sektor pertanian yang tumbuh subur di Indonesia adalah sub sektor perkebunan karena pada umumnya tanaman perkebunan sangat cocok ditanam di tempat yang beriklim tropis dan subtropis seperti Indonesia. Tanaman perkebunan dapat dikelompokan menjadi dua berdasarkan karakteristiknya, yaitu tanaman semusim dan tanaman tahunan. Tanaman semusim adalah tanaman yang bisa dipanen satu kali dengan siklus hidup setahun satu kali; contohnya adalah tembakau, tebu, dan kapas. Sedangkan tanaman tahunan membutuhkan waktu yang panjang untuk berproduksi. Tanaman tahunan ini bahkan dapat menghasilkan sampai puluhan tahun dan bisa dipanen lebih dari satu kali; contohnya adalah kopi, lada, kelapa sawit, dan karet (Suwarto et al, 2014). Tanaman perkebunan tahunan yang tumbuh subur di Indonesia salah satunya adalah kopi.

Tanaman kopi yang dikembangkan di Indonesia ada dua jenis yaitu arabika dan robusta. Menurut Rukmana (2014), Indonesia merupakan negara penghasil kopi arabika terbaik di dunia. Direktorat Jendral Perkebunan (2014) menyatakan provinsi Jawa Barat pada tahun 2013 merupakan penghasil kopi arabika terbesar di pulau Jawa (Lihat Tabel 1).

Tampak bahwa Kabupaten Bandung merupakan penghasil kopi arabika terbesar yakni 6.637 ton dengan produktivitas 0,99 . Namun, dari segi produktivitas Kabupaten Bandung masih berada di bawah Kabupaten Sukabumi, Bandung Barat dan Kabupaten Bogor. Hal itu menunjukan Kabupaten Bandung berpotensi sangat besar untuk mengembangkan kopi arabika.

\section{Tabel 1}

Produksi Kopi Arabika Tahun

2013 di Provinsi Jawa Barat

\begin{tabular}{|c|c|c|c|}
\hline 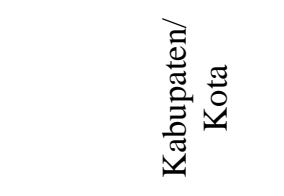 & 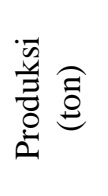 & 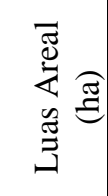 & 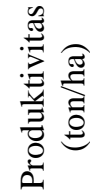 \\
\hline Kab. Bandung & 6.637 & 6.687 & 0,99 \\
\hline Kab. Garut & 1.308 & 1.438 & 0,91 \\
\hline Kab. Sukabumi & 607 & 538 & 1,13 \\
\hline Kab.Bandung Barat & 597 & 481 & 1,24 \\
\hline Kab. Bogor & 101 & 101 & 1,00 \\
\hline Kab. Cianjur & 78 & 258 & 0,30 \\
\hline Kab. Subang & 50 & 95 & 0,52 \\
\hline Kota Tasikmalaya & 5 & 8 & 0,62 \\
\hline Kab. Majalengka & 1 & 2 & 0,50 \\
\hline Kab. Bekasi & 1 & 4 & 0,25 \\
\hline
\end{tabular}

Sumber: Direktorat Jenderal Perkebunan, 2014

Kopi arabika dan robusta yang dikembangkan di Indonesia dapat ditingkatkan nilai tambahnya dengan diolah menjadi kopi luwak. Keistimewaan kopi luwak adalah kopi tersebut dimakan luwak dalam bentuk buah kopi. Kemudian, buah tersebut mengalami fermentasi di perut luwak. Setelah itu buah tersebut akan keluar bersama kotoran luwak dalam bentuk yang utuh. Kopi luwak memiliki cita rasa yang unik, kadar asam rendah dan lembut seperti sirup (Marcone, 2004; Chan dan Gracia 2011). Harga kopi luwak cukup fantastis yaitu $\mathrm{Rp}$ 600.000-1.300.000 per kg dalam bentuk greenbean kopi arabika (Panggabean, 2011), atau Rp 45.000100.000 per gelas. Pada umumnya kopi luwak arabika rasanya asam, sedangkan kopi luwak robusta pahit.

Salah satu usaha kopi luwak yang ada di Kabupaten Bandung adalah Kelompok Tani Kiwari Farmers. Kiwari Farmers 
membudidayakan kopi luwak arabika sejak tahun 2015. Kelompok tani ini terletak di Kampung Pondok Buahbatu Cikawari, Desa Mekarmanik, Kecamatan Cimenyan, Kabupaten Bandung.

Permintaan kopi luwak di Kiwari Farmers rendah dan tidak kontinyu. Ketidakpastian ini menyebabkan Kiwari Farmers kewalahan untuk menghabiskan sisa kopi luwak yang belum terjual. Pada Tabel 2 disajikan perbandingan jumlah produksi dan penjualan yang sangat timpang. Berdasarkan Tabel 2, Kiwari Farmers mampu memproduksi kopi luwak $180 \mathrm{~kg}$ selama setahun (Mei 2016 sampai dengan Juni 2017). Namun, yang terjual hanya $16,3 \%$ atau $83,7 \%$ yg tidak terjual. Hal ini perlu dicari penyebabnya dengan mengidentifikasi kekuatan internal dan eksternal Kiwari Farmers sehingga pada gilirannya nanti dapat dirumuskan strategi yang terbaik bagi Kiwari untuk memasarkan kopi luwaknya.

Tabel 2

Jumlah Produksi Kopi Luwak (Green Bean) Manglayang Karlina di Kiwari Farmers Tahun 2016-2017

\begin{tabular}{|l|c|l|c|}
\hline \multicolumn{2}{|c|}{ Produksi } & \multicolumn{2}{c|}{ Penjualan } \\
\hline Bulan & $\begin{array}{c}\text { Hasil } \\
(\mathrm{Kg})\end{array}$ & Bulan & $\begin{array}{c}\text { Hasil } \\
(\mathrm{Kg})\end{array}$ \\
\hline Mei & 50 & Agustus & 3,685 \\
Juni & 40 & September & 2,765 \\
Juli & 30 & Oktober & 6,320 \\
Agustus & 30 & November & 4,560 \\
September & 10 & Desember & 3,420 \\
Oktober & 20 & Januari & 2,100 \\
& & Februari & 1,320 \\
& & Maret & 1,260 \\
& & April & 4,359 \\
& & Mei & 2,380 \\
\hline Jumlah & 180 & Jumlah & 29,360 \\
\hline
\end{tabular}

Sumber: Kiwari Farmers, 2017.
Perumusan strategi pemasaran Kiwari didasarkan pada analisis yang menyeluruh terhadap pengaruh faktor-faktor lingkungan eksternal dan internalnya. Lingkungan eksternal perusahaan setiap saat berubah dengan cepat sehingga melahirkan berbagai peluang dan ancaman baik yang datang dari pesaing utama maupun dari iklim bisnis yang senantiasa berubah. Konsekuensi perubahan faktor eksternal tersebut juga mengakibatkan perubahan faktor internal perusahaan, seperti perubahan terhadap kekuatan maupun kelemahan yang dimiliki perusahaan tersebut (Rangkuti, F. 2006). Menurut David (2006), strategi pemasaran adalah strategi yang disatukan, luas, terintegrasi, dan kompeherensif yang dirancang untuk memastikan bahwa tujuan pemasaran dari perusahaan dapat dicapai melalui pelaksanaan yang tepat oleh organisasi. Lebih lanjut David (2006) menyatakan bahwa ada 4 tipe strategi pemasaran yaitu strategi integrasi, strategi intensif, strategi diversifikasi dan strategi defensif.

Berdasarkan uraian di atas, penelitian ini bertujuan untuk merumuskan berbagai strategi alternatif untuk pemasaran kopi luwak Manglayang Karlina di Kiwari Farmers, kemudian memilih strategi prioritas di antara berbagai strategi alternatif itu.

\section{Metode Penelitian}

Desain penelitian menggunakan desain kualitatif dengan teknik penelitian studi kasus. Jenis data yang dikumpulkan berupa data primer dan sekunder. Data primer diperoleh melalui wawancara dengan informan internal dan eksternal serta melakukan pengamatan langsung (observasi) ke lapangan. Informan internal adalah direktur, $\mathrm{CEO}$, dan bagian marketing Kiwari Farmers, sedangkan informan eksternal terdiri dari konsumen, dan pihak Golden Malabar selaku pesaing. Data primer mengenai gambaran umum, visi, misi, tujuan, sasaran serta informasi mengenai lingkungan internal dan eksternal Kiwari 
Farmers. Data sekunder diperoleh melalui studi literatur meliputi penelitian terdahulu, buku teks, jurnal, internet, dokumen Kiwari Farmers. dan literatur lain yang terkait dengan topik penelitian.

Variabel yang diukur dari konsep strategi pemasaran adalah:

1. Lingkungan internal:

Harga: harga jual, penetapan harga, sistem pembayaran, periode pembayaran.

Distribusi: saluran pemasaran, cakupan pasar, sarana transportasi, system jual

Promosi: promosi penjualan, tenaga penjualan, media promosi.

2. Lingkungan eksternal:

Ekonomi: perkembangan harga kopi, pengaruh naik turunnya harga, pengaruh perkembangan kopi di Jawa Barat,

Alam: kecocokan agroklimat dengan pertumbuhan tanaman kopi arabika, kendala alam pada proses produksi, cara menyikapi kendala faktor alam, perkembangan banyaknya populasi luwak.

Teknologi: pengaruh penerapan teknologi berbasis produksi, ada tidaknya subsidi dari pemerintah.

Kebijakan: ada tidaknya kebijakan pemerintah daerah tentang luwak.

Sosial budaya: ada tidaknya faktor budaya yang diimplementasikan, berubah tidaknya pola konsumsi masyarakat, dan berubah tidaknya selera konsumen.

Konsumen: jenis konsumen, perkembangan jumlah konsumen,

Pemasok: bermitra / tidaknya dengan pemasok.

Pesaing: jenis pesaing, jumlah pesaing, asal pesaing.

Analisis data dilakukan melalui beberapa tahap yaitu 1) identifikasi faktor internal dan eksternal menggunakan matriks IFAS dan EFAS, 2) penentuan posisi Kiwari Farmers dengan matriks IE berdasar EFI (evaluasi terhadap matriks IFAS) dan EFE (evaluasi terhadap matriks EFAS), 3) perumusan strategi alternatif dengan matriks SWOT, dan 4) memilih strategi prioritas menggunakan matriks QSPM.

Berapapun banyaknya faktor yang dimasukan ke dalam matriks EFI, jumlah nilai yang dibobot dapat berkisar 1,0 (terendah) hingga 4,0 (tertinggi), dengan rata-rata 2,5. Total skor yang dibobot di atas rata - rata menggambarkan organisasi kuat secara internal.

Total bobot yang tinggi menggambarkan respon perusahaan terhadap peluang dan ancaman sangat baik. Total skor terendah menggambarkan perusahaan tidak memanfaatkan peluang dan tidak menghindari ancaman.

Kemudian disusun matriks internaleksternal (IE) seperti terlihat pada Gambar 1. Matriks IE dibagi menjadi tiga daerah utama yang memiliki implikasi strategi berbeda. Pertama, rekomendasi untuk divisi yang masuk dalam sel I, II, atau IV, dapat digambarkan sebagai tumbuh dan kembangkan. Strategi intensif (penetrasi pasar, pengembangan pasar, dan pengembangan produk) atau integratif (integrasi ke belakang, integrasi ke depan, dan integrasi horizontal) adalah strategi yang paling sesuai untuk divisi - divisi ini. Kedua, divisi yang masuk dalam sel III, V, atau VII dapat memilih strategi jaga dan pertahankan; penetrasi pasar dan pengembangan produk dapat menjadi alternatif untuk divisi ini. Ketiga, rekomendasi yang diberikan untuk divisi yang masuk dalam sel VI, VIII, dan IX adalah tuai atau divestasi.

Selanjutnya disusun matriks SWOT seperti yang tampak pada Tabel 5. 
Tabel 5

Matriks SWOT

\begin{tabular}{|c|c|c|}
\hline EFAS & $\begin{array}{l}\text { Strength } \\
5-10 \text { faktor } \\
\text { kekuatan } \\
\text { intenal }\end{array}$ & $\begin{array}{c}\text { Weakness } \\
\text { 5-10 faktor } \\
\text { kelemahan } \\
\text { internal }\end{array}$ \\
\hline $\begin{array}{l}\text { Opportuniti } \\
\text { es }(O) \\
5-10 \\
\text { Faktor- } \\
\text { Faktor } \\
\text { Peluang } \\
\text { Eksternal }\end{array}$ & $\begin{array}{l}\text { Strategi } S O \\
\text { Ciptakan } \\
\text { strategi yang } \\
\text { menggunaka } \\
\text { n kekuatan } \\
\text { untuk } \\
\text { memanfaatk } \\
\text { an peluang. }\end{array}$ & $\begin{array}{l}\text { Strategi } W O \\
\text { Ciptakan } \\
\text { strategi yang } \\
\text { meminimalk } \\
\text { an } \\
\text { kelemahan } \\
\text { untuk } \\
\text { memanfaatk } \\
\text { an peluang. }\end{array}$ \\
\hline $\begin{array}{l}\text { Threats }(T) \\
5-10 \\
\text { Faktor- } \\
\text { Faktor } \\
\text { Ancaman } \\
\text { Eksternal }\end{array}$ & $\begin{array}{l}\text { Strategi } S T \\
\text { Ciptakan } \\
\text { strategi yang } \\
\text { menggunaka } \\
\text { n kekuatan } \\
\text { untuk } \\
\text { mengatasi } \\
\text { ancaman. }\end{array}$ & $\begin{array}{l}\text { Strategi } W T \\
\text { Ciptakan } \\
\text { strategi yang } \\
\text { meminimalk } \\
\text { an } \\
\text { kelemahan } \\
\text { dan } \\
\text { menghindari } \\
\text { ancaman. }\end{array}$ \\
\hline
\end{tabular}

Sumber: Rangkuti, F (2006)

Untuk menentukan strategi prioritas digunakan matriks QSPM yang melakukan evaluasi pilihan strategi alternatif secara objektif, berdasarkan key success factor internal external yang telah diidentifikasikan sebelumnya dengan analisis SWOT. Caranya dengan menetapkan kemenarikan relatif (relative atractiveness) dari strategi-strategi yang diperoleh melalui SWOT, lalu dipilih satu strategi terbaik (prioritas). Ada 6 langkah dalam penyusunan matriks QSPM, yaitu:

a. Membuat daftar peluang atau ancaman eksternal kunci dan kekuatan atau kelemahan internal kunci.

b. Memberi bobot pada setiap faktor eksternal dan internal kunci.

c. Memeriksa matriks-matriks pencocokan
(SWOT) dan mengenali strategi-strategi alternatif yang harus dipertimbangkan. Menuliskan strategi pada baris atas QSPM.

d. Menentukan nilai daya tarik (AS), (1 : tidak menarik; 2: agak menarik; 3: wajar menarik; 4: sangat menarik). Nilai daya tarik adalah angka yang menunjukkan daya tarik relatif masing-masing strategi pada suatu rangkaian alternatif tertentu.

e. Menghitung TAS = total nilai daya tarik dengan cara mengalikan bobot dengan nilai daya tarik masing-masing baris. Total nilai daya tarik menunjukkan daya tarik relatif dari masing-masing strategi alternatif, dengan hanya mempertimbangkan dampak dari faktor keberhasilan kritis eksternal atau iunternal yang berdekatan. Semakin tinggi total nilai daya tarik semakin menarik suatu alternatif tersebut.

f. Menghitung jumlah total nilai daya tarik. Menjumlahkan total nilai daya tarik masing-masing kolom strategi QSPM. Semakin tinggi nilainya semakin menarik strategi tersebut.

Startegi alternatif yang memiliki total nilai daya Tarik (TAS) tertinggi yang akan menjadi strategi prioritas.

\section{Hasil dan Pembahasan}

\section{Keadaan Umum Kiwari Farmers}

Kiwari Farmers meliputi Warung Kopi Kiwari, restoran Bumi Kiwari, Kiwari Superindo Dago, Kiwari Superindo Rajawali, dan kebun kopi. Warung kopinya terletak di Jl. Palapa No.55, Padasuka, Cimenyan, Bandung, Jawa Barat 40911. Kebun kopi arabikanya yang seluas 2 hektar terletak di Kampung Pondok BuahbatuCikawari, Desa Mekarmanik, Kecamatan Cimenyan, Kabupaten Bandung. Lokasi Perkebunan yang berada di kaki Gunung Manglayang dengan ketinggian kurang lebih 1100 MDPL merupakan lokasi yang sangat cocok untuk ditanami tanaman kopi terutama kopi arabika mengingat komoditas tesebut merupakan komoditas yang cocok 
ditanam pada ketinggian di atas 1000 MDPL. Hal ini tentunya merupakan keuntungan bagi Kiwari Farmers.

\section{Tabel 6. Analisis Matriks IFAS}

\begin{tabular}{|c|c|c|c|}
\hline Faktor Internal & $\begin{array}{c}\text { Bobot } \\
\text { Rata- } \\
\text { rata } \\
\end{array}$ & $\begin{array}{c}\text { Rating } \\
\text { Rata- } \\
\text { rata }\end{array}$ & $\begin{array}{c}\text { Skor } \\
\text { Rata- } \\
\text { rata } \\
\end{array}$ \\
\hline \multicolumn{4}{|l|}{ Kekuatan } \\
\hline $\begin{array}{l}\text { memiliki konsep } \\
\text { mandiri dari hulu } \\
\text { hingga hilir }\end{array}$ & 0.061 & 4 & 0,244 \\
\hline $\begin{array}{l}\text { menerapkan standar } \\
\text { animal welfare dalam } \\
\text { memelihara luwak }\end{array}$ & 0.100 & 4 & 0,400 \\
\hline $\begin{array}{l}\text { menerapkan } \\
\text { pemberdayaan } \\
\text { masyarakat dalam } \\
\text { perekrutan tenaga } \\
\text { kerja }\end{array}$ & 0.077 & 4 & 0.308 \\
\hline $\begin{array}{l}\text { memiliki produk } \\
\text { inovasi beragam yang } \\
\text { belum dimiliki } \\
\text { perusahaan sejenis }\end{array}$ & 0.094 & 4 & 0.376 \\
\hline $\begin{array}{l}\text { selalu melakukan } \\
\text { kampanye kreatif } \\
\text { edukasi tentang kopi }\end{array}$ & 0.094 & 4 & 0.376 \\
\hline Jumlah & 0,426 & & 1,704 \\
\hline \multicolumn{4}{|l|}{ Kelemahan } \\
\hline Jumlah SDM kurang & 0,088 & 2 & 0,176 \\
\hline $\begin{array}{l}\text { Saluran pemasaran } \\
\text { kopi luwak masih } \\
\text { terbatas }\end{array}$ & 0,105 & 1 & 0.105 \\
\hline $\begin{array}{l}\text { Sarana prasarana } \\
\text { pasca panen belum } \\
\text { memadai }\end{array}$ & 0.122 & 2 & 0.244 \\
\hline $\begin{array}{l}\text { Pengembangan tenaga } \\
\text { kerja belum optimal }\end{array}$ & 0.111 & 2 & 0.222 \\
\hline $\begin{array}{l}\text { Riset pengolahan } \\
\text { roasting belum } \\
\text { optimal }\end{array}$ & 0.144 & 2 & 0.288 \\
\hline Jumlah & 0.57 & & 1,035 \\
\hline Jumlah Total & & & 2.739 \\
\hline
\end{tabular}

Pemasaran dilakukan Kiwari secara on-line, penjualan kepada mitra, serta penjualan langsung di Warung Kopi Kiwari, restoran Bumi Kiwari, dan ritel di Superindo dalam bentuk roast bean, ground bean, green bean, coldbrew, dan kopi seduh. Harga kopi luwak roast bean $\mathrm{Rp} 950$ per $\mathrm{kg}$, green bean $\mathrm{Rp}$ 400.000 (kualitas biasa) dan Rp 1.200.000 (kualitas baik), atau Rp 45.000 per gelas, dan coldbrew Rp 60.000 per botol. Sedangkan untuk roast bean Arabika Manglayang Karlina dijual dengan harga Rp 235.000/kg, ground bean Rp35.000/200 gram atau Rp 15.000/gelas, serta coldbrew Rp 35.000 per botol. Kopi arabika Manglayang Karlina tidak ada yang dijual dalam bentuk green bean.

\section{Analisis Faktor Internal (IFAS)}

Menerapkan standar animal welfare dalam pemeliharaan luwak merupakan kekuatan utama dengan skor 0,400 (lihat Tabel 6). Prinsip animal welfare merupakan standar yang dikeluarkan oleh kementerian berupa peraturan yang mengatur tata cara pemeliharaan luwak yang berdasarkan prinsip kesejahteraan hewan yang tertera pada PERATURAN MENTERI PERTANIAN REPUBLIK INDONESIA NOMOR 37 / Permentan / KB.120 / 6 / 2015 tentang cara produksi kopi luwak melalui pemeliharaan yang memenuhi prinsip kesejahteraan hewan. Kandang luwak milik Kiwari dibuat dengan sanitasi yang baik, luas, serta nyaman bagi luwak. Dilengkapi dengan sarang dari kayu berukuran sama dengan sarang pada habitat aslinya yaitu 60 x 40 x $1200 \mathrm{~cm}^{3}$. Selain itu dilengkapi juga dengan kayu dan bambu sebagai sarana bermain bagi luwak.

Saluran pemasaran kopi luwak yang masih terbatas merupakan kelemahan utama dari Kiwari dengan skor 0,105. Saluran pemasarn kopi luwak Kiwari Farmers bervariasi, mulai dari konsumen yang datang ke warung hingga pengunjung paket.

Jumlah skor rata-rata kekuatan $(=1,704)$ lebih besar daripada jumlah skor rata-rata kelemahan $(=1,035)$. Hal ini menunjukkan bahwa Kiwari Farmers mampu menggunakan kekuatannya untuk menutupi kelemahan yang dimiliki. 


\section{Analisis Faktor Eksternal (EFAS)}

Media pemasaran murah dan bervariasi merupakan faktor peluang yang mendapat respon paling kuat dari Kiwari Farmers, dengan skor 0,416 (lihat Tabel 7). Salah satu pemasaran yang diterapkan adalah bekerja sama dengan komunitas-komunitas kreatif yang berdomisili di Kota Bandung. Hal ini memudahkan Kiwari Farmers mencari media pemasaran dan memperluas pengaruhnya. Teknologi internet memudahkan Kiwari dalam menentukan media pemasaran yang murah, seperti media sosial Instagram dan Facebook, serta market place seperti bukalapak.com dan tokopedia.com.

Kondisi cuaca yang tidak stabil merupakan ancaman utama bagi Kiwari Farmers dengan skor 0,083 . Hujan pada musim hujan tahun 2017 memang berlangsung selama berbulanbulan; hal ini di luar dugaan. Musim kemaraunya pun demikian. Akibatnya, hasil panen menurun.

Jumlah skor rata-rata peluang $(=1.726)$ lebih besar daripada jumlah skor rata-rata ancaman $(=1,114)$, hal ini menunjukkan bahwa Kiwari Farmers mampu menggunakan peluang yang ada untuk menghadapi ancaman.

Tabel 7

Analisis Matriks EFAS

\begin{tabular}{|l|c|c|c|}
\hline $\begin{array}{c}\text { Faktor } \\
\text { Eksternal }\end{array}$ & $\begin{array}{c}\text { Bobot } \\
\text { Rata- } \\
\text { rata }\end{array}$ & $\begin{array}{c}\text { Rating } \\
\text { Rata- } \\
\text { rata }\end{array}$ & $\begin{array}{c}\text { Skor } \\
\text { Rata- } \\
\text { rata }\end{array}$ \\
\hline \multicolumn{4}{|l|}{ Peluang (Opprtunity) } \\
\hline $\begin{array}{l}\text { Kopi Jawa Barat } \\
\text { semakin dikenal }\end{array}$ & 0,100 & 4 & $\mathbf{0 , 4 0 0}$ \\
\hline $\begin{array}{l}\text { Fatwa MUI } \\
\text { menyatakan } \\
\text { bahwa kopi } \\
\text { luwak halal } \\
\text { untuk } \\
\text { dikonsumsi }\end{array}$ & 0,105 & 3 & 0,316 \\
\hline
\end{tabular}

\begin{tabular}{|l|c|c|c|}
\hline $\begin{array}{l}\text { Jumlah } \\
\text { peminum kopi } \\
\text { meningkat }\end{array}$ & 0,077 & 4 & 0,311 \\
\hline $\begin{array}{l}\text { Media } \\
\text { Pemasaran } \\
\text { murah dan } \\
\text { bervariasi }\end{array}$ & 0,138 & 3 & $\mathbf{0 , 4 1 6}$ \\
\hline $\begin{array}{l}\text { Masyarakat } \\
\text { mulai tertarik } \\
\text { dan semakin } \\
\text { peduli terhadap } \\
\text { petani kopi }\end{array}$ & 0,094 & 3 & 0,283 \\
\hline Jumlah & 0,514 & 2 & $\mathbf{1 , 7 2 6}$ \\
\hline Ancaman (Threat) & \multicolumn{2}{|l|}{} & $\mathbf{2}$ \\
\hline $\begin{array}{l}\text { Isu negatif } \\
\text { pemeliharaan } \\
\text { luwak dalam } \\
\text { budidaya kopi } \\
\text { luwak }\end{array}$ & 0,083 & 2 & 0,166 \\
\hline $\begin{array}{l}\text { Kemajuan } \\
\text { teknologi }\end{array}$ & 0,105 & 3 & 0,316 \\
\hline Populasi luwak & 0,083 & 2 & 0,166 \\
\hline $\begin{array}{l}\text { Kondisi cuaca } \\
\text { yang tidak stabil }\end{array}$ & 0,083 & 1 & $\mathbf{0 , 0 8 3}$ \\
\hline $\begin{array}{l}\text { Terdapat produk } \\
\text { subtitusi } \\
\text { terhadap kopi } \\
\text { luwak }\end{array}$ & 0,127 & 3 & $\mathbf{2 , 8 4 4}$ \\
\hline Total & 0,481 & & \\
\hline
\end{tabular}

\section{Analisis matriks IE}

Matriks IE merupakan tahap pencocokan antara kekuatan dan kelemahan internal dengan peluang dan ancaman eksternal. Mencocokan faktor keberhasilan kunci eksternal dan internal adalah kunci untuk menghasilkan alternatif strategi yang layak secara efektif (David, 2006). Berdasarkan hasil analisis matriks IFAS dan EFAS, posisi Kiwari Farmers terletak pada kuadran V, yaitu jaga dan pertahankan. 
Alternatif strategi yang dapat digunakan adalah strategi intensif, yaitu strategi yang merekomendasikan Kiwari Farmers untuk melakukan penetrasi pasar dan pengembangan produk. Penetrasi pasar dapat dilakukan dengan cara promosi lebih gencar lagi melalui berbagai media maupun wadah pemasaran lainnya serta menjalin kemitraan dengan tujuan perluasan pemasaran. Kemudian strategi pengembangan produk adalah memodifikasi atau mengolah produk tersebut menjadi produk yang lebih bervariasi dengan tujuan memperluas segmen pasar.

\section{Analisis matriks SWOT}

Penyusunan matriks SWOT dilakukan untuk analisis kondisi internal maupun eksternal dengan tujuan memperoleh alternatif strategi yang tepat bagi Kiwari Farmers. Berdasarkan posisi Kiwari Farmers yang telah dipaparkan di atas, dapat dirumuskan matriks SWOT yang hasilnya berupa strategi alternatif sebagai berikut:

1. Memperluas pemasaran yang berlandaskan edukasi terhadap masyarakat mengenai konsep mandiri dari hulu hingga hilir dan animal welfare terkait kopi luwak Jawa Barat. Media pemasarannya yang digunakan dapat yang murah saja dan bervariasi.

2. Mempertahankan dan menambah inovasi produk kopi luwak Jawa Barat yang lebih bervariasi untuk memperluas pasar dan memperbanyak produk khas Kiwari Farmers.

3. Meningkatkan riset pengolahan roasting dan pengembangan tenaga kerja. kualitas, pemasaran, sehingga diharapkan volume penjualan kopi luwak meningkat, baik penjualan kepada masyarkat peminum kopi maupun bukan peminum kopi.

4. Mengembangkan riset hulu dan sarana prasarana untuk meningkatkan standar kebun kopi agar masyarakat awam dan petani kopi yang berminat mempelajari kopi dari hulu hingga hilir dapat diakomodasi dengan baik.
5. Melakukan kampanye kreatif berbasis edukasi yang dilakukan di pusat pemasaran mengenai animal welfare yang diterapkan Kiwari Farmers dan tentang kopi luwak pada umumnya, agar pemahaman masyarakat akan kedua hal itu meningkat.

6. Menginvestasikan profit untuk melakukan riset pada proses roasting, pengembangan tenaga kerja, dan pengembangan sarana dan prasarana pada proses hulu. Ini berguna dalam menambah varian inovasi turunan kopi luwak. Selain itu juga memudahkan proses inovasi dengan harapan angka penjualan kopi luwak akan meningkat serta segmentasi pasar meluas dengan pemasaran terpusat di Warung Kopi Kiwari.

\section{Analisis matriks QSPM}

Tahap terakhir dari perumusan strategi adalah menyusun matrks QSPM untuk memilih strategi prioritas/strategi terbaik yang dapat diterapkan oleh Kiwari Farmers.

Tabel 8

Matriks QSPM

\begin{tabular}{|c|c|}
\hline $\begin{array}{c}\text { Alternatif Strategi } \\
\text { ke: }\end{array}$ & Nilai TAS \\
\hline 1. & 5,335 \\
\hline 2. & 5,103 \\
\hline 3. & 5,270 \\
\hline 4. & 5,293 \\
\hline 5. & 5,442 \\
\hline 6. & $\mathbf{5 , 6 2 4}$ \\
\hline
\end{tabular}

Matriks QSPM diperoleh dari hasil analisis SWOT yang berupa keenam buah strategi alternatif yang telah disebutkan di atas. Total nilai daya Tarik (TAS) bagi setiap alternatif strategi dapat dilihat pada Tabel 8. Nilai TAS tertinggi didapat oleh strategi alternatif ke enam. 
Jakarta

\section{Kesimpulan}

Kelompok Tani Kiwari Farmers dapat memasarkan kopi luwak Manglayang Karlina dengan berbagai strategi yaitu: 1) mengalokasikan keuntungan untuk riset fermentasi biji kopi, dan proses roasting, untuk pelatihan formal tenaga kerja, serta untuk pembangunan lantai jemur dan gudang, 2) melakukan kampanye kreatif berbasis edukasi mengenai animal welfare, dan jenis, manfaat serta proses pengolahan kopi luwak, 3) menggunakan Instagram dan Facebook untuk mengedukasi konsep pengolahan mandiri dari hulu hingga hilir dan animal welfare, 4) memperluas jalan kebun, lantai jemur, dan tempat pengolahan pasca panen kopi untuk kepentingan agrowisata, 5) meningkatkan riset pengolahan roasting dan pelatihan tenaga kerja, serta 6) mempertahankan dan menambah inovasi produk baru dan kemasan. Namun strategi terbaik adalah strategi pemasaran kesatu.

Disarankan Kiwari Farmers mengimplementasikan strategi ke 1. Selain itu juga melakukan survei terhadap konsumen kopi luwak.

\section{Daftar Pustaka}

AAK.1988. Budidaya Tanaman Kopi. Yogyakarta: Kansius

Arianto, Dani. 2013. "Pelaksanaan Pengawasaan Proses Kopi luwak Dalam Upaya Menjaga Kualitas Pada Perseoran Terbatas Pada PTPN XII Kebun Kalisat Jampit Bondowoso". Artikel Ilmiah

Asosiasi Eksportir Kopi Indonesia. 2001. Laporan Buletin Tahunan Pengurus Besar Asosiasi Eksportir Kopi Indonesia. Jakarta: Asosiasi Eksportir Kopi Indonesia.

Cannon, Perreault, Mc Charty. 2008. Pemasaran Dasar. Salemba Empat:
David, Fred.R. 2004. Manajemen Strategis Konsep-konsep, Alih Bahasa Kresno Santoso. Jakarta: PT Indeks Kelompok Gramedia.

David, Fred R. 2006. Manajemen Strategis : Konsep Edisi 10 Diterjemahkan oleh Pauly Sulistio dan Haryadin Mahardika. Jakarta : Salemba Empat.

Direktorat Jendral Perkebunan. Statistik Perkebunan Indonesia 2015-2017 Kopi. Jakarta.

Direktorat Jendral Perkebunan. Statistik Perkebunan Indonesia 2013-2015 Kopi. Jakarta.

Fuad, M, Christin, H, Nurlela, Sugiarto, Paulus Y,E,F. 2006. Pengantar Bisnis. Gramedia Pustaka: Jakarta

International Coffee Organization. 2017. "Konsumsi Domestik Kopi di Indonesia"

(https://www.indonesiainvestments. com/id/bisnis/komoditas/kopi/item 1 86?). Diakses pada 4 Februari 2018.

Kementrian Pertanian Republik Indonesia. 2015. "Cara Produksi Kopi luwak Melalui Pemeliharaan Luwak Yang Memenuhi Prinsip Kesejahteraan Hewan". Melalui < http://perundangan.pertanian.go.id/p menteri.php?awal $=100$ \&page $=6>$ [14/11/2017]

Kotler, Philip., dan Gary Armstrong., 1997, Dasar-Dasar Pemasaran, Edisi ketujuh, Jilid 1, ,Prenhallindo:Jakarta

Nilasari, Senja. 2014. Manajemen Strategi. Dunia Cerdas: Jakarta Timur

Panggabean E. 2011a. Menggeruk Untung dari Bisnis Kopi luwak. Agromedia Pustaka: Jakarta. 
Purnomo, S dan Zulkieflimansyah. 2007. Manajemen Strategi Ed. Revisi. Lembaga Penerbit Fakultas Ekonomi Universitas Indonesia.

Rangkuti, Freddy. 2006. Analisis SWOT Teknik Membedah Kasus Bisnis. Gramedia Pustaka Utama: Jakarta.

Rahardjo, Pudji. 2012. Panduan Budidaya dan Pengolahan Kopi Arabika dan Robusta. Penebar Swadaya: Jakarta.

Rukmana, Rahmat. 2014. Untung Selangit dari Agribisnis Kopi. Yogyakarta: Lily Publisher.

Soetrisno, Lukman. 2002. Paradigma Baru Pembangunan Pertanian. Kansius: Yogyakarta.

Sofyan Assauri. 1999. Manajemen Pemasaran. Dasar, Konsep, dan Strategi. Jakarta: PT. Raja Grafindo Persada.

Stanton, William J. 1994. Prinsip Pemasaran. Edisi Ketujuh, Jilid 2. Jakarta: Erlangga.

Sucahyo, Nurhadi. 2016. Produsen Kopi Luwak Perbaiki Upaya Pemenuhan Hak Satwa.

(https://www.voaindonesia.com/a/pr odusen-kopi-luwak-perbaiki-upayapemenuhan-haksatwa/3376806.html). Diakses pada 4 Februari 2018.

Umar, Husein. 2002. Strategi Management In Action. PT. Gramedia Pustaka Utama: Jakarta.

Umar, Husein. 2005. Evaluasi Kinerja Perusahaan. PT. Gramedia Pustaka Utama: Jakarta.

Umar, Husein. 2008. Riset Pemasaran dan Perilaku Konsumen. Gramedia Pustaka Utama: Jakarta. 